\title{
Learning outside the walls of the classroom: Engaging the digital natives
}

\author{
Andrea K. Veira \\ St. Vincent Girls' High School, St. Vincent and the Grenadines \\ Coreen J. Leacock \\ The University of the West Indies, Cave Hill Campus, Barbados
}

\author{
S. Joel Warrican \\ The University of the West Indies Open Campus, Barbados
}

\begin{abstract}
This study investigated the response of students and teachers to the use of ICTs to promote teaching and learning outside of the classroom and regular school hours in a Caribbean secondary school. Following an action research design, Grades 10 and 11 Biology students were given access to subject content and learning support through online discussion groups (Google and Facebook), a website that hosted information and an accompanying blog. Data were collected by questionnaire, interviews, and observation. Initially, the students were reluctant to use the discussion groups, though they eventually reported that these facilities provided useful learning support outside of the classroom. They however rejected the Google group in favour of the more familiar Facebook group. Students were so enthusiastic about these resources that they requested that more subject areas be added. Teachers were somewhat reluctant to answer this call, citing the lack of access to equipment and time as deterrents. One year later, the initiative had expanded to the point where the school had acquired additional equipment, had devised a policy for ICT use, additional resources were added to the website and increasingly, students were using their portable devices for academic purposes both in and out of school.
\end{abstract}

\section{Introduction}

Computers have become an integral part of human lives, more so than any other dominant technology ever invented (Oludipe, 2009). He further explains that we are in an age where the use of information and communications technology (ICT) is expected to make pedagogy more student-friendly. Wheeler (2001) states that ICT will inevitably proliferate into classrooms and the role of the teacher must change to accommodate ICT. He asserts that with ICT in the classroom, certain teaching resources like chalkboards will become obsolete and certain forms of assessments redundant as multimedia presentations and quicker forms of assessment and feedback are utilised by technology. This view is supported by Watson (2001) who states that Information Technology serves as the catalyst for change in teaching style, learning approaches and access to information. However, the automatic adoption of these new technologies should not be expected, since as Watson notes, teachers are somewhat threatened by this change. While this seems to be a global phenomenon, there are those schools which are embracing the change and making efforts to incorporate ICT into the teaching and learning process. For example, Pearson and Naylor (2006) report that some education institutions in the UK are taking advantage of the power of the technology to transform pedagogic practices and are pushing ahead with innovative projects.

Here in the Caribbean region, the importance of ICT as a catalyst for facilitating national development through the transformation of education systems has been recognised. Many of these countries (for example Barbados, St. Kitts and Nevis, Trinidad and Tobago and St. Vincent and the Grenadines) are seeking to include ICT and Information Technology in their curricula, and have introduced policies and initiatives to that end. In Barbados, the Education Sector Enhancement Programme (ESEP) was introduced in the year 2000. Though it was an overall education reform, a major emphasis was on equipping schools with ICTs (Barbados Ministry of Education, Youth Affairs and Sport, 2003). In St. Kitts and Nevis, computer labs were introduced in schools in 1998 and new policies to improve on ICT facilities and developments were re-established in 2006 (Gaible, 2009). Similarly, the installation of computer labs in all of its existing secondary schools was identified as a key component of Trinidad and Tobago's Secondary Education Modernisation Programme (SEMP) (Burgess et al., 2011). This is in keeping with the view that ICT is critical to the transformation of the education system in that country 
and for preparing students to function in an ever-changing global environment (TT, Ministry of Education, 2010, 2012). Evidently then, the trend regionally is towards the implementation of ICT in national education systems. This is also the case in St. Vincent and the Grenadines.

St. Vincent and the Grenadines (SVG) is a small state comprising a group of 32 islands (9 of which are inhabited) located in the archipelago of the Eastern Caribbean. This small group-island state covers an area of 389 square kilometres and is home to approximately 110,000 people. Although the use of technology in the classroom is somewhat of an innovation in SVG, Vincentians have long had access to a wide range of technological tools. For example, mobile phones are very prevalent, with the National Telecommunication Regulatory Commission in the country reporting that in 2009, there were 121,114 pre- and post-paid mobile telephone subscriptions (NTRC, 2011). The use of this technology spanned all generations. Also common are other portable devices such as tablets, Kindles and laptops. Access to the Internet is also widely available. Indeed, according to the NTRC (2011), there were 12,155 residential Internet subscribers, representing $37 \%$ of the households in the country. Internet speed within households ranges from 1 to 4 megabytes per second. Furthermore, through government initiatives, rural and underserved communities have access to free wireless Internet services at a speed of 8 megabytes per second. This provision is made via public buildings such as schools and community learning resources centres.

As is the global trend, computer technology has made its way into educational institutions at all levels in SVG, where in 2010, the government introduced a policy to adopt new technologies as tools for teaching and learning. In order to ensure that its citizens develop twenty-first century skills, the SVG government embarked on an initiative that involves gradually providing all students with access to computer technology through a "One-Netbook-Per-Child" scheme. One aim, among others, is to ensure that learners are technologically literate in order to access national, regional and world-wide employment opportunities (St. Vincent and the Grenadines Ministry of Education, 2011). In harmony with this national policy, efforts are being made to encourage schools to use ICTs for handling student records with information management systems, for enhancing learning, and as tools for research and communication. This trend is facilitating the introduction of new and creative educational practices designed to increase students' interest and motivation to engage with the content of the different subjects that they study. A good way of doing this is to make use of the devices for which young people seem to have great enthusiasm and that they often have in their possession. Pearson and Naylor (2006) show that the ownership of multimedia-capable mobile phones, portable music players and mobile computing devices is increasing rapidly among students in schools, though students often find that many of the skills and the knowledge they acquire informally are not valued within the school setting. Needless to say, the discrepancy between what is valued by students and schools makes the use of such devices challenging. These challenges are further exacerbated by the fact that teachers often appear to be less comfortable and/or competent at using these devices than are their students.

The presence of such portable devices among the students in a secondary school in SVG triggered the interest in investigating their use as means of facilitating students' learning outside the walls of the classroom and at more flexible times. Thus, the purpose of the study reported here was to investigate the views, practices and experiences of students and teachers in relation to the implementation of an initiative to use ICTs to promote teaching and learning outside of the classroom and regular school hours. This is very appropriate in this context because, although relatively prevalent, portable electronic devices are not widely used for educational purposes. There is evidence to suggest that these devices when used with other facilities such as the Internet and social networking sites can provide students with alternative avenues for engaging with subject content (Trucano, 2005). Through the Internet, students are learning twenty-first century skills on their own at home while at school they are mostly engaged in passive learning activities since they are not allowed to multi-task with their gadgets: chatting, blogging, reading or playing video games (Schrum \& Levin, 2009). This is also true of students in SVG. The notion of these students using their gadgets for educational purposes, that is, capitalising on their use of technology to improve their learning arose. However, since students are not allowed to have some of these gadgets at school, the teacher-researcher became interested in investigating the students' use of these technologies as tools for learning outside of the school. 


\section{Perspectives on students' IT use and competence}

As is the case elsewhere, there is the common perception in SVG that students are more knowledgeable, more competent and keener in relation to ICTs than the older generations, often including many of their teachers. Indeed, many have embraced the concept of students as "digital natives" as expounded by Prensky (2001). Pushing this perspective, Prensky implies that all young people born in the era of pervasive technology will demonstrate competence with said technology even if no formal instruction is given. There is however evidence to suggest that the idea of global competence may not be sound. Indeed, it has been argued that there may be nuances to students' IT use, and that there is in fact only a very narrow range of activities in which a large proportion of students engage, with the majority of ITrelated activities pursued by a minority of students (Bennett \& Maton, 2010). For example, research has shown that there are some technology-related activities - such as game playing and content creation - in which fewer young people than one would expect of digital natives, engage (Salaway \& Caruso, 2007; Maton \& Bennett, 2010). Some (e.g. Selwyn, 2009) advance the idea that rather than being competent, expert users of technology, many young people are in fact disempowered, disenchanted and alienated when it comes to technology-related activities.

The debate over what Selwyn (2009) describes as the exaggerations and inconsistencies associated with applying Prensky's (2001) concept of digital natives to the younger generation continues. It cannot be denied though, that students are all different and that using an all-inclusive term to label them is inaccurate and misleading. Evidence suggests that students are not all experts with the technology, and that many students lack the competence with the technology to adequately benefit from its use in the classroom (Li \& Ranieri, 2010; Calvani, Fini, Ranieri, \& Picci, 2012). Perhaps the difference between students who were born into the world of technology and the older generation upon whom the technology was thrust, is that the younger generation is more open to its use and more willing to experiment with it in new settings. This openness and acceptance of the technology may be what some interpret as comfort, confidence and competence. Indeed, a study done in SVG revealed that students, like their teachers, needed training in the appropriate use of the technology. When these students encountered a problem with the technology, they would "try things until something worked" (Leacock, Warrican \& Veira, 2013), sometimes with adverse outcomes to the machines. In contrast, when their teachers encountered challenges, sometimes even minor ones, generally their first instinct was, rather than try something, to seek assistance from elsewhere, including from the students who they considered to be experts (Warrican, Leacock, Veira \& Thomas, 2012). Despite this, what is evident is that the technology is pervasive and that, whether they are keen or not, students must be helped to capitalise on the educational benefits it presents.

This more realistic picture of students' competence with technology raised questions about the nature of their experiences with this technology as learning tools.

\section{Online facilities as educational tools}

Even though there may be some debate about the level of technology expertise students may have, one thing that seems to emerge from the research is that the activity in which the majority of young people, including students, engage is social networking (Bennett \& Maton, 2010; Clark, Logan, Luckin, Mee \& Oliver, 2009). These activities allow them to share their lives and interests with others using the Internet (Hung \& Yuen, 2010; Zaidieh, 2012). Social networking is a member of the family of what are commonly called Web 2.0 tools: web-based resources designed to encourage collaboration and sharing. They include not only social networking sites (e.g. MySpace, Facebook and Twitter), but also sites that support services such as blogs and wikis (Gaffer, Singh \& Thomas, 2011; Hung \& Yuen, 2010; Zaidieh, 2012). It is however noteworthy that social networking sites are found to be more frequently used by students than are the other Web 2.0 tools (Bennett \& Maton, 2010). This finding is borne out in the context of SVG, where it was found that students from as low as Grade 3 use these social-networking facilities, but made no mention of other Web 2.0 tools (Leacock, Warrican \& Veira, 2013). This fact, along with the availability of portable devices among the students of the school involved, contributed to the activities around which this paper is centred. The paper seeks to record the experiences of a class of students as they were introduced to the use of Web 2.0 tools for learning outside of the classroom. 
There is no doubt that today's students have a knack for making use of technology for communicating (Eynon, 2009). For these young people, communication is not limited to face-to-face interaction, expensive telephone calls or letter writing. For them, the use of online facilities for sharing appears to be second nature and online sites are inundated by students who communicate with each other this way. Papp (2010) explains that social networks and virtual worlds are some of the most popular and widely used applications in existence on the Internet, and that they allow students the convenience of searching for information and learning when they want to, rather than when they have to. The popularity and pull of social networking sites and their value in academic contexts is recognised by some schools that use these facilities for activities such as updating students on sporting and academic information, making contact with students and taking virtual field trips in other countries as part of their learning process for subjects such as Science and Geography (Davis, 2010). The fact that students are already using these communication facilities on their portable devices has perhaps contributed to teachers' efforts to integrate them into the teaching and learning transactions.

The notion of using social networking for learning is supported by writers such as Hunter, Laursen and Seymour (2006), who indicate that learning is largely a social process, which is enriched when students are able to conceptualise and critically think about academic problems with others. This is perhaps the reason that online social networks are the popular trend with students and why educators are now seeking to use them for pedagogical purposes. When an environment exists where students are communicating freely with persons including their peers about various matters and are doing this daily by means of portable devices that connect online, then it seems prudent for teachers to capitalise on this facility to improve student learning. As Matthews, Andrews and Adams (2011) explain, social learning spaces help to facilitate student involvement in their learning through social experiences. They point to the example of a university where a science learning centre was created with access to wireless networks and rooms for socialising. This resulted in frequent visits to the centre between classes to socialise and to seek academic help from peers who were able to explain difficult concepts to those seeking help. It is this independent student-centred learning that is desirable in modern classrooms that are seeking to move away from the traditional teacher-centred practices. The use of online forums like blogs and social networks can therefore assist the process of educating students by engaging them and creating comfortable spaces in which they can communicate with each other to learn. The use of portable devices and social networks therefore can facilitate group work or peer tutoring using technology.

The availability of Internet services along with its accessibility by means of the various portable devices makes another resource a viable option as an instructional tool: websites. According to McMullin (2005), a website can be a repository of information like a library, which allows students to readily access material at will. McMullin also points out that websites are convenient mechanisms for dissemination of resources. This implies that teachers can use websites to post information that students can use to acquire knowledge, thus releasing them from having to provide notes. This can help to transform classrooms into student-centred environments that actively engage the students, creating a sense of belonging and student ownership of the learning process. Apart from being a repository, a website can facilitate the use of web logs or blogs. Blogging is a facility that promotes independent learning by allowing students to reflect on the knowledge acquired and shared, and to explore various thoughts about the particular topics under discussion. Blogging is described as both the construction of a personal knowledge artifact and an ecological practice, which presents emergent knowledge as a series of common, dynamically linked spaces (McMullin, 2005; O'Donnell, 2006). Like social networks, this can be a powerful tool for developing reflective and independent learners in a student-centred classroom (Helmer \& Bloch, 2010). O'Donnell (2006) also suggests that students can be encouraged to use blogs to post research notes, stories and reflections throughout their studies. He indicates that blogs can be a forum in which students critique the work of their peers. Since the creation and reaction to blogs can be accomplished using portable devices, this facility presents another excellent technological tool that educators can use to promote learning outside of the walls of the classroom and regular school hours.

The value of technology for facilitating learning outside of the classroom and of regular school hours cannot be overlooked. One limitation of face-to-face learning environments is that they take place at specified times and often a limited amount of information is discussed. The availability of technology in the form of portable and other devices with Internet connectivity allows students to have access to content relevant to the studies at any time and to engage meaningfully in asynchronous discussion of said content 
(Gilbert \& Dabbagh, 2005). Consequently, students who prefer to study at times outside of the regular opening hours for school can do so.

It is the availability of these online facilities (e.g. the Internet) and the presence of portable communication devices that prompted interest in the use of these resources to promote learning among students in a secondary school in SVG, and to investigate students' and teachers' reactions to their use. This investigation was undertaken by a Biology teacher at the school, taking on the role of a researcher in conjunction with two other researchers, university lecturers who are interested in the use of technology in education.

\section{Methodology}

This study sought to answer the question: what are the views, practices and experiences of students and their teachers in relation to the implementation of ICTs to promote teaching and learning outside the classroom and regular school hours. For this purpose, an action research design was adopted. This design was deemed appropriate since, according to Gay, Mills and Airasian (2009), action research permits education practitioners to conduct systematic enquiry in the teaching-learning context. Furthermore, this research design allows for close collaboration between all stakeholders (Cohen, Manion \& Morrison, 2000) as they seek to bring about sustainable change (Warrican, 2006). In this case, a problem was identified (how to minimise the interference to the summer break for the students and teachers who must engage in the summer session) and a solution was sought. Based on the teacher-researcher's observation of the prevalence of portable and other electronic devices, the solution involved the introduction of ICTs for educational purposes, not only during the summer session, but also during the school term to engage the students outside of regular classroom and school hours. In keeping with the tenets of action research, the idea was sold to the students and their teachers in order to win their cooperation and willing participation in the initiative. The aim was to initiate a sustainable change in how students and teachers engage in the teaching-learning process, making use of powerful technology available to them. In accordance with the nature of action research, a cyclical process that involved the cooperation and collaboration of all the participants was followed: the initial solution was implemented and data were collected and analysed. Then, based on the findings, a revised plan was devised and implemented. Data were also collected and analysed during this second cycle. The feedback from this cycle was also used to make adjustments to the innovation of using ICTs for out-of-school learning purposes. This paper reports on the first two cycles or phases of the action research process.

\section{Participants}

The research was conducted with fourth and fifth form (grades 10 and 11) students in an all-girl secondary school in SVG and their teachers, where the teacher-researcher was a teacher of Biology. The first phase of the research was conducted with 65 Biology students who were participating in an annual summer programme designed to prepare the students for the upcoming academic year of study. The second phase or cycle involved 218 students from the major subjects pursued at the school, namely the sciences, the liberal arts and business. All the students involved were taking classes in information technology. Data were also collected from teachers of the students involved in the study.

\section{Data collection}

During the first phase of the study, data were collected by questionnaire and observation. The questionnaire was designed to collect data about the students' views on the usefulness of the electronic resources; their feelings about using the resources, and solicited suggestions for improving the resources that were being offered. Students practices in relation to the electronic resources were also observed to determine the extent to which the students were using them.

During the second phase, data were collected by focus group interviews with a sample of students selected from the classes that had access to the online resources. Two groups, (one with grade 10 students and the other with grade 11 students), each with five students, were involved. For each group, one student from each of the five classes at the grade levels was randomly selected for participation. During the focus group interviews, students were asked about their awareness of the website, its content, parents' awareness of its existence, frequency of use, quality of information, types of games and impact on 
understanding. Along with the focus group interviews, a whole class discussion was also conducted with 22 students in one of the Grade 11 Biology classes. This discussion addressed issues such as their feelings about the website, its usefulness, the Google and Facebook groups, as well as any challenges they experienced using them. Semi-structured interviews were also conducted with the teachers (Chemistry, Integrated Science, Biology, Visual Arts and Information Technology) who used the online facilities in their practice during the research period.

\section{Data analysis}

Data from the questionnaire were compiled and were analysed using descriptive statistics in the form of frequencies. The observation data were used to determine which facilities the students were using, how frequently they were using these facilities and for what purpose, where possible. The archival records of interactions between the teacher-researcher and the students and among the students themselves, including email and postings on the discussion boards, were also examined for evidence of practices, views and experiences of the students. Furthermore, the interview data were explored for themes that shed light on the views and practices of the students in relation to the use of their electronic devices to access the resources, as well as on any successes and challenges that the students experienced. Where appropriate during both phases of the study, feedback from the students via these data was used to modify the teaching and learning resources that were made available.

\section{The teaching and learning activities}

As was mentioned earlier, the idea to investigate the use of ICTS to facilitate teaching and learning outside of educational purposes in a school in SVG was conceived after it was noticed that the students at the school had access to such devices. Since there was no guidance as to what the students would like and find useful, a decision was made that the teacher-researcher would try out some resources with her Biology students, and based on their feedback, the resources would be modified and shared with the wider school population. Thus, the first phase of the research was planned and implemented.

Phase 1 of the research ran from June to August 2010, over the summer vacation period. In SVG, as is the case in other Caribbean countries, students entering the fourth and fifth forms at the secondary level (grades 10 and 11) are often given assignments and/or attend classes organised by their teachers to help to prepare them for the next academic year. After noticing the students' apparent affinity for communicating using electronic devices such as smartphones and tablets, the teacher-researcher decided that, rather than have her students come to the school for extra tuition and assistance with their Biology summer assignment, she would make the resources available to the students using online communication resources, namely a Google group. This group contained links to sites and prepared notes relating to the content relevant to the assignment, past examination papers and a discussion board. In order to sell the idea to the students and their other teachers, the teacher-researcher shared information with them and explained how the initiative would work. Additionally, the information about the online availability of the summer assignment and the related resources, along with detailed instructions about how to access them, was sent to the students via email. At this time, another Biology teacher at the school, Ms. Zen, expressed interest in engaging her students in this way, and her students were also given access to the Google group.

After monitoring the students' initial use of the Google group, the teacher-researcher and her colleague noticed that some students were not signing on to the group. Since many of the students already had Facebook accounts, Ms. Zen then created a Facebook page with the intention of grabbing the attention of those students who did not join the Google group. Thus, throughout the summer vacation, the teacherresearcher and Ms. Zen shared information with their students by posting additional resources relating to the summer assignment to the Google group and the Facebook page. They also engaged the students in discussion and encouraged the students to engage in discussion among themselves. The use of these online resources was monitored throughout the summer period, with attention also being paid to the students' comments relating to their experiences.

Phase 2 of the research was conducted during the first term of the next academic year (September to December 2010). At the start of this period, a questionnaire was administered to the Biology students who used the online resources during the summer and the teacher-researcher also held discussions with the students in her classes to find out how useful the groups were to them and their general feelings about 
learning in this way. Based on the findings from the data collected from these students, the electronic resources were revised and Phase 2 of the research was designed. Revision included the discontinuation of the Google group, the retention of the Facebook page, and the creation of a website that provided online learning support for the students. Initially, the website, which was constructed by the teacherresearcher, contained only resources for the Biology students (e.g. lists of topics, notes, assignments, labs, games, videos and pictures). This then served as a model for introducing teachers in other subject areas to the website as a means of engaging in the teaching and learning transaction outside of the regular school hours.

Teachers in the Sciences, Visual Arts and Information Technology all expressed interest in using the website as a repository of information to which their students could have access outside the classroom and out of regular school hours. Thus, students had online out-of-regular-school-time access to instructional resources in Biology, Chemistry, Integrated Science, Information Technology and Visual Arts. Apart from instructional material, the teacher-researcher created a blogging space for Biology, and placed a link on the website. The purpose of this space was to facilitate interaction/discussion between the teacher and the students and among the students. During this phase, data were collected from both students and teachers to determine their views on the use of these technologies as tools for facilitating teaching and learning, especially during times when school was closed.

\section{Findings and discussion}

As mentioned earlier, the use of the ICTs to facilitate teaching and learning out-of-regular-school-hours was initiated in June at the end of the academic year, and data collection for the first phase of the action research was done primarily during the summer vacation (July and August). As is the nature of action research, there was constant interaction between the researchers and the other participants. Below are findings from this first phase of the study garnered from questionnaires, archival data from the discussion boards and other communication between the students and the teacher-researcher, and how these findings informed the second phase. Except for the teacher-researcher, all other names used are pseudonyms.

\section{Early practices, experiences and views of students using ICTs to learn outside the school walls}

Initially, the existence of the Google group as an alternative to the regular face-to-face summer programme normally put on by teachers at the school was communicated to the Biology students. Since the students were joining on a voluntary basis, it took some time for many of them to sign on, even though encouraging emails were sent to them. Table 1 below indicates the number of students who signed on to the Google group, by month.

Table 1

No. of students who joined the Google group, by month

\begin{tabular}{lccc}
\hline Month (2010) & June & July & August \\
\hline $\begin{array}{l}\text { Number of students joining the } \\
\text { Google group }\end{array}$ & 24 & 24 & 1 \\
\hline
\end{tabular}

Despite initial expressions of willingness by the students, the number of users registered on the Google group was somewhat low, as only $37 \%$ of the 65 students had signed on by the end of June. Consultation with the students shed some light on this low usage. For example, students indicated that they found this mode of communication too public and some of them were reluctant to use it as others would become privy to their queries (and by extension, their apparent lack of knowledge), as illustrated by the comment below, sent by email to the teacher who was encouraging her to participate in the Google group:

Ms. I don't really know what to say. Do I have to? Ms, when I look at what the others wrote there isn't anything left for me to say and suppose what I say is wrong? I don't really want everyone seeing my stuff if it is wrong. (Kristy, Gr 11) 
Some students were more comfortable with emailing the teachers where the interaction would be between them and the teacher only. This is illustrated in the below email exchange between the teacher-researcher and a student.

Kristy: hi miss v, I am confused with all that you have told everyone and so im askin for myself [Four Biology-related questions listed]. Thank you :D

Miss. V: Kristy, place these on the discussion board and check there for a response.

Kristy: Plz ans the questions plzzzzzzzzz jus want a straight ans

Here, the student did not want to use the Google group discussion board, but merely wanted the teacher to answer her queries by email, privately. Indeed, for some students, this sentiment continued into the second phase of the study, even though the teacher-researcher pointed out that with the use of the discussion boards, other students would benefit from advice being given. This is evident in the next exchange. This exchange also highlights another factor that contributed to the initial low usage of the Google group: challenges with signing on.

Shelly: Hi miss. In the project rite for number 1 ,are you doin the causes etc. for the example that you give. and do you have to give cause, symptoms for both the example given in plants and in animals? so would it be two tables that you are doing one for animals and one for plants?

Ms. V: Shelly, I would like you to kindly copy and paste all of your questions onto the discussion board on the google group. I will respond there for the benefit of everyone. Thanks

Shelly: miss do you have to draw the cycles of the insects? cant $u$ get something from the internet...and ummm fro number one..can $u$ do like two tables..like one for plants and one for animals...and i'm confused..isntit one example for like each type of disease and for that example you give the cure and so...plz clarify for me...sryy miss but I dont understand how to post the stuff and so

Ms. V: Shelly, you need to post these queries on the group. Go to the group, where you see discussions, look to the right hand side of that and you will see new post. Click on it (new post), write your questions and I will respond there. When I respond you will get an email and you can go to the group, click on your discussion and read.

Shelly: miss if i new how iwud have

Ms. V: Send me your phone number.

Shelly: [An SVG number given]. but miss i'm kinda in canada. but anyway the phone number for the house here is ...

Ms. V: Ok Shelly, I'm not going to call Canada. You have used the discussion board before and I've replied though....why arent you able to get through? If you go on the group and click on discussions or new post what do you see?

Two things are evident here. First, some students had difficulties signing on to the Google group. This was a source of frustration for them, as illustrated by the student's response to the teacher's suggestion that she post her queries to the group (miss if $i$ [k]new how I w[o]u[l]d have). Indeed, during the interviews, when asked about their experiences with the Google group, several of the students spoke of difficulties. For example, one girl said:

The $[\mathrm{G}]$ oogle group is good but it gives me trouble. When I sign in it would say that I am not a part of the group. (Shella, Gr 10) 
The second thing that is evident is a benefit of using ICTs in this way. Regarding the conversation with Shelly above, the student was in Canada, but was still able to be in touch with her teacher and colleagues and was able to obtain guidance and assistance as she worked on her assignments.

To address the reluctance to use the Google group, the teacher-researcher and her colleague, Ms. Zen, decided to respond only to queries posted to the discussion board rather than to those sent by email. Additionally, students were given assistance and clarification in relation to the signing on process. Consequently, by the end of July, $74 \%$ of the 65 students were using the Google group to interact with their teacher and their peers about the summer assignment, though under duress in some cases. The students were still reluctant to respond to posts, and in fact, days passed before there was any response. Recognising this reluctance to respond on the Google group, and having reflected on the fact that the students were on summer vacation, the teacher-researcher decided to add some familiarity to the discussion by using the board in a manner familiar to the students: social connecting. She appealed to the students' emotions and acknowledged their possible feelings of being overwhelmed. The following discussion ensued:

Ms. V (Jul 19, 9:10pm): Are you tired and fed up of the assignments and labs in what is supposedly called a vacation?

Shanta (Jul 20, 8:39pm): Absolutely fed up!

Ms. V (Jul 21, 11:29am): Hang in there, the prize at the end will be worth it! However, try to pace yourself so that you at least get some sleep and rest during the break...

This was in fact the first time that students responded to one of the teacher's posts within a twenty-four hour period. This marked the beginning of sharing among peers and with the teachers through the group. However, though some students openly used the board for help with the assignment, others continued to make requests by email. Of note here though is the nature of the requests from the students. They now tended to ask for links and websites rather than asking the teachers to give them information, indicating their willingness to engage with the available resources themselves. For example, one student wrote:

im getting along great wid d assignment, but...can $\mathrm{u}$ send me a link wid physiological diseases in plants plz. i checked textbooks [and] went online but icant find anything. (Request from the Google Group Discussion Board)

This willingness to use these technologies to find information that they need for educational purposes even though they avoided the discussion board, suggests that perhaps the reluctance to use the Google group stemmed from fear of exposing their academic selves in a public forum more than anything else and hence the emailed requests. Indeed, this notion finds some support in the fact that, once the teacherresearcher introduced a more social aspect (see excerpt of conversation with Shanta above), the students more openly used the discussion board to talk about issues such as the stress they were feeling as they worked on their assignments.

In action research, adjustments are often made to the initiative as it evolves. In this case, based on the reluctance of some students to use the Google group for discussion, a Facebook group was introduced at the start of August. It was felt that since many of the students already had Facebook accounts and as Papp (2010) suggests, tended to live out their lives in online environments through social networks, they may be more amenable to this alternative. Indications are that within six hours of its creation, 12 students had signed on to the group. The Facebook group provided access to the same resources that were available on the Google group. This group was monitored primarily by Ms. Zen. While there are no specific details about the pervasiveness, frequency and nature of its use, the students were asked about the Facebook group as well as the Google group on the questionnaire that was administered to the students when the summer session was over and during the interviews.

On the questionnaire, the students were asked about their use and views of the resources provided. The data collected indicated that the students found all of these materials useful, with no resource being ranked as useless. Table 2 below shows the proportion of the students who responded to items relating to 
the use of the Google Group Discussion Board and the Facebook Wall. Not all of the students responded to each item on the questionnaire, hence totals do not add up to $100 \%$ of the 63 students.

Table 2

Percentage of students who gave various responses to items about the two discussion groups

\begin{tabular}{lcccccc}
\hline \multirow{2}{*}{ Feature } & \multicolumn{2}{c}{ Agree (\%) } & \multicolumn{2}{c}{ Unsure (\%) } & \multicolumn{2}{c}{ Disagree (\%) } \\
\cline { 2 - 7 } & Google & Facebook & Google & Facebook & Google & Facebook \\
\hline Is a waste of my time & 8 & 0 & 10 & 5 & 52 & 54 \\
Is useful to my work & 65 & 49 & 5 & 8 & 0 & 2 \\
Allows interaction with my peers & 48 & 51 & 13 & 2 & 5 & 6 \\
Allows interaction with my teachers & 60 & 56 & 3 & 0 & 6 & 3 \\
Is not necessary & 3 & 3 & 11 & 6 & 54 & 48 \\
\hline
\end{tabular}

Note. $n=63$

Of note in the table above is that favourable opinions about the usefulness and scope for interaction were held by comparable proportions of students in all but one item: [The group] is useful to my work. For this item, $16 \%$ more of the students agreed with this statement for the Google group than they did for the Facebook group. This discrepancy may be linked to the fact that the teacher overseeing the Facebook group somewhat veered away from the original plan This may appear anomalous, especially in light of evidence (presented later) that indicated that the students preferred the Facebook group. However, a possible reason for the discrepancy is evident in these comments that were made during the interview:

[The teacher] generally tells us about things via email or emails direct information for class so even though she tells us to use the groups ... we just do it if we feel like. (Zeena, Gr. 11)

[The teacher] emails us information directly ... We are always on Facebook so we check the [Facebook] group but it's like we couldn't be bothered because [the teacher] doesn't seem to be bothered. All along it was always like this, even with the group from summer. (Paula, Gr. 11)

Apparently then, in her efforts to help the students who were experiencing some frustration and discomfort using the Facebook group, much of the information that this teacher provided was not posted to the Facebook group, which was under her care. Indeed, in one exchange on the Facebook group, a student made a request of the teacher-researcher. When she responded, the student thanked her and added that the other teacher had already given her a response. Since that response did not appear on the Facebook wall, the implication is that the response was given elsewhere (more than likely, via email). Thus, others with a similar query would not have benefited from it and as such, the usefulness of the group to some students might have been affected. Generally though, the students recognize the value of both groups as a means of interacting with their peers and teachers. What is evident though is that these interactions were not restricted to academic areas only. The students also wanted to use the space to socialise with each other even as they sought help from their peers and teachers.

Despite the fact that the Facebook group was reportedly found useful by fewer students than was the Google group, the students still reported a preference for the Facebook group over the Google group, with $41 \%$ of the sixty three students who responded to the questionnaire expressing dislike for the layout and design of the Google group while only $6 \%$ expressed such feelings for the Facebook group. Reasons for this preference emerged during the interviews with the students. The comments below illustrate this:

Kristy: The colour is pretty, it is easier to follow and it gives me a reason to go on Facebook so I prefer it to Google.

Sally: The responses on Facebook are better and the notification of anything new comes through whenever we students go on Facebook.

Kristy: If Google had a filter, it would be better.

Shella: The process of adding the Facebook group is just shorter. 
Risa: Facebook is prettier and much easier to follow.

Greeta: I think it should just be Facebook alone because it is so much easier to follow.

The students here clearly found Facebook easier to access and to use because they were already accustomed to this social networking facility.

In order to make a decision about the continuation of the project after the summer vacation, the students' views were sought on the questionnaire. The data showed that $81 \%$ of students wanted the groups to continue in the new school year. They also suggested that fun activities such as games, quizzes and videos be placed on the groups, that more subjects be added and that a more accessible discussion board be set up for the Google group. Taking these suggestions into consideration, a decision was taken to extend the project into the new academic year, with the following modifications:

- The development of a website with a student-friendly design and layout to attract more students;

- The replacement of the Google group by a blog with a link on the website;

- The retention of the Facebook group as a notification system.

In addition, provisions were made for resources from other subject areas to be added to the website. These modified provisions were taken into the second phase of the project to make educational opportunities available to the students outside of the classroom and of regular school hours.

\section{Phase two: Extending ICT resources to facilitate learning out of the classroom}

Phase Two of the project got underway in September 2010. At the start of the academic year, the website was set up. Apart from Biology, resources were also available for four other subject areas: Information Technology, Chemistry, Integrated Science and Visual Arts. At that time, it was only available to students in Grades 10 and 11 at the school. The Grade 11 students were primarily those students who were in Grade 10 during Phase One. The blog and Facebook facilities that were available via the website were those set up by the teacher-researcher for the Biology students. Other teachers were however free to create these facilities for their students. In order to gauge responses to the website and the concept of learning outside the walls of the classroom, activity was monitored and interviews were conducted with students and teachers.

Evidence revealed that generally, the idea of the website received good support from students, teachers and parents. For example, though parents were not asked directly what they thought, comments from the Grade 11 students during the focus group interviews indicate that they thought the website would help their children. When asked what their parents had to say when they were informed, the following comments were made:

Kia: My mom said "I hope you use the site more than Facebook" and she usually checks on me when I am on the computer.

Olivia: I gave them the letter they didn't say anything, they just took it and read it.

Lanny: My mom wanted to see the site after the letter, and she asked me if I use it. I told her yes and she said okay.

Teanne: My mom said it was a good thing, because if I miss work because I'm absent I would be able to access notes.

Students were pleased with the games in the Biology section as they had requested after Phase One. They also liked having access to laboratory assignments for Biology and Information Technology and the resources for Visual Arts. Indeed, during the interviews, students appeared to be very enthusiastic about the website. In fact, they even shared ideas about resources that they felt would be useful on the website. For example, they wanted more fun activities in other subject areas besides Biology; they wanted more subjects added, for example, Physics, Economics, English Literature and foreign languages. They 
suggested ideas for links that they would find useful, for example, Sparknotes and performances of books being studied for literature as well as links to translators for foreign languages. There were several requests for video clips. In fact, during one conversation where the students were discussing the need for more videos and other graphics, one student commented:

When things are online on computer, my eyes are wide open even if I'm tired once graphics are present. There are video clips of Denzil Washington acting as Troy in a Literature book that our teacher told us about. More of this would be useful. (Olivia, Gr 11)

Apart from this, students also commented on the impact of the website on their learning. For example, in addressing this issue in the focus group interview, the following conversations ensued:

Cindy: Yes, the notes help a lot.

Molly: Yes, it keeps me up to date and I'm going to try to play the soccer game Cece was talking about when I go home.

Anna: Yes, for instance the notes on cigarette smoking and tables are easier to remember and I learnt things I didn't know before for the cigarette smoking one.

Cece: Yes, because it is easier to get notes when they are posted rather than having to go and make them. I do not like the picture or the colours though [on the website's home page]; want to see that changed.

These four students, like several others interviewed, felt that the website was helping them as they grappled with subject content. Generally then, there was a level of excitement, enthusiasm and motivation as the students spoke. There was an indication that they were taking control of their own learning.

Students also appeared to like the idea of the blog; they seemed to prefer it to the Google Group Discussion Board that was previously used. During the focus group interview, when students were discussing how they used the website, the blog was mentioned quite often. This is well illustrated in the conversation below:

Lanny: I use [the website] to access information for Information Technology, Biology and Chemistry regularly and to comment on the [Biology] blog which I think is a very good idea because you get to read different answers and learn things you didn't know. For instance, the past paper questions for the Form 4 [Grade 10], I was reading through their answers and learning things I didn't know.

Sally: I use it for SBAs and the blog is cool, I like it.

Teanne: I like the general idea of questions and reading the answers from everyone on the blog but I would like games that are related to the notes more.

The idea of the blog is so well accepted that a bit later in this conversation, another student while expressing what she thought would enhance the website said:

[The website] just needs more subjects like Maths, English B, History, French and Spanish. For History the teacher can put up information on the different persons we learn about in class, and for English B, miss can put up summaries for the books. I want more practice for Maths. More fun activities would be good too, like puzzles, games, and more blogs. [emphasis added]. (Kia, Gr 11)

Again here, the students expressed interest in materials to improve their own learning which leads back to the problem solving and constructivism skills discussed by Frei, Gammill and Irons (2007) and Reeves (1998) respectively. They also expressed their desire to have a common space in which to voice opinions and share them with their peers through the blogging phenomenon. McMullin's (2005) description of 
websites as repositories of information and blogs as places for social learning and expressions from students is therefore applicable here.

Apart from students, the teachers were interviewed to find out about their experiences and views in relation to the website and the resources there. One issue of concern was that though several of the teachers expressed interest in posting resources to the website, only four of them actually did. During the interviews, this matter was addressed. Evidence suggests that teachers felt that they did not have sufficient access to the equipment that would facilitate the design and production of these resources. For example, the coordinator of the club for one of the subjects stated that she was interested in placing the club's activities on the site but that no one seemed to have a camera to record their activities. Another teacher who placed instructional material on the site expressed similar sentiments:

I would like some computers and projectors at least in the [subject] room for the grades ten and eleven students, to incorporate it into teaching and then utilise the website more effectively and also use power points...I would like a Wacom screen along with the site. It is like a touch screen, you draw on it directly. It is more fun for students instead of traditional means. It is a more innovative way to teach especially in a modern context...

Another factor that apparently contributed to teachers' reluctance to use the website was their perception that it would require extra work to prepare the material to be posted. For example, during the interview, one teacher stated:

The workload is the limitation. I will have to make a conscious effort to try to help by posting materials per topic as they are taught. A projector and the Internet would help a lot because I would then be able to teach using those and the website to increase students' interest. (Mr. Henry, a teacher)

As was the case with other teachers, Mr. Henry also pointed to the challenge of equipment as a deterrent. The third factor that affected teachers' use of the website, somewhat related to the previous factor, is time. It is apparent that they struggled to find the time to provide the type of material that the students requested. In fact, two of the teachers interviewed used the same words when discussing this issue. They both said "The problem is time". Thus, evidently, though the teachers may have recognised the usefulness of the website, preparing and posting instructional material were apparently limited by insufficient equipment for production of said material along with insufficient time to deal with what they perceived to be extra work in addition to their regular duties. Like the students, some teachers recognised the benefits of using the technology for learning both outside the walls of the classroom as well as within, and felt that the website was having a positive impact on student learning. For example, during the interview, Ms. Zen remarked:

The website is helping in some way. For example, a student Teanne, is improving. She usually does not do well on exams or when it comes to answering past paper questions. Now, she answers questions better. The blog is definitely helping with answering of Caribbean Examination Council type questions...

This is indeed good commendation for the project, despite the challenges that the teachers reported. But these challenges are not insurmountable, with some creativity. These factors may merely be the teachers' mechanisms to avoid activities with which they may not be comfortable or competent. This appears to be in harmony with the notion that if teachers are not comfortable with innovations, then they are reluctant to embrace them (Fullan, 2007), even though they may think that the innovation is necessary or beneficial. The apparent vast divide between the students' relative ease of use of the technology and the teachers' competence presents a challenge here. The desires and needs of the students who are willing to learn in this environment may call for skills that are beyond individual teachers. These findings suggest that for success and sustainability, a whole school approach with support and guidance for teachers may be a viable solution to this. 


\section{One year later}

The data for the second phase of the research were collected during the first term of the 2010-2011 academic year (Sep-Dec), but the teacher-researcher continued to administer the website with a view to making it an integral part of the learning environment for the students at the school. Based on feedback from the second cycle of the action research process, the teacher-researcher continued to encourage her colleagues to consider using the website and other tools to facilitate learning out of regular hours. She made presentations during staff meetings, devised and conducted training sessions for her colleagues and demonstrated how the ICTs could be integrated into the instructional process. She also worked on securing some commitment from the school's administration to the initiative and to find ways to address the issues and concerns raised by the other teachers who were still reluctant to embrace the innovation. The research team therefore decided to have a follow up look at the school one year after the project was introduced. What was found was encouraging, and suggests that though there were (and continued to be) challenges, the use of technology to facilitate learning outside of the classroom was still being practiced in the school. In fact, there were developments that boded well for this innovation.

For example, the website was still active and resources for more subjects were added. In addition, for some subject areas, resources were added for students in grades other than 10 and 11. Furthermore, using a proposal prepared by the teacher-researcher, the school was able to acquire equipment requested by the teachers through the school's fundraising committee: mimio pads, mimio teach devices, projectors, laptops, speakers, presenters, video camera, digital camera, digital microscope and projector lamp replacements, surge protectors and adapters. The school also constructed a storage cupboard and installed a security alarm system to house and protect the equipment. This equipment was augmented by projectors, white boards and netbooks that were part of the government's one-netbook-per-student initiative. With the net book initiative, grade 7 (the only grade that was issued the net books at the time) students who did not have their own devices were able to access the website and benefit from the resources there.

Perhaps one of the most encouraging signs of the sustainability of the change to the teaching and learning culture of the school is the fact that the school devised a policy on the use of this technology. This policy not only addressed the use of the school's equipment, but also students' use of portable devices (e.g. iPads, Samsung tablets, Nooks and Kindles) at school, since increased numbers of students were bringing their devices with them to school. Students were using these devices to take notes in classes and download learning resources (from the website and textbooks from commercial sellers), and the teacherresearcher reported that emails she received from students commonly ended with the phrase "Sent by my iPad" or "Sent by my blackberry device" or even "Sent by my iPhone", a sure sign that the students are using their portable devices as an integral part of their learning experiences. In the meantime, the teacherresearcher is continuing to facilitate development activities for the teachers at the school.

\section{Conclusion}

This action research project was undertaken to explore students', and to a lesser extent their teachers', views, practices and experiences in relation to the use of ICTs as tools for learning outside of the classroom and regular school hours. The online resources were introduced during the summer when the students in Grade 10 would normally have a face-to-face summer session to prepare them for the upcoming school year. Based on feedback from the students involved in the summer session, the resources were revised, expanded to include a website and a blog, and made available during the first term of the new academic year. The report here shares findings from these two cycles of the research process. Some main findings are summarised below:

- Initially, students had difficulties accessing the resources provided via a Google group;

- Students were reluctant to use the discussion boards for academic purposes, apparently due to fear of exposing their lack of knowledge;

- Over time, students' requests for information were replaced by requests for online sources of information (e.g. links to useful websites);

- Students seemed to prefer using a Facebook wall for discussion and interaction over a Google group; 
- Students found the ICT provisions useful to facilitate interaction with their peers and teachers even when they were abroad;

- Students were enthusiastic about the online availability of instructional resources (e.g. on a website) that they could access at any time;

- Despite acknowledging the usefulness of the online resources for their students, several of the teachers who initially expressed interest in the activities were reluctant to embrace the innovation;

- Teachers blamed limited time for preparation and lack of access to appropriate equipment for their reluctance to use the website as a repository for instructional material.

These findings shed some light into the use of ICTs by these students who Prensky (2001) would include in the group of so-called digital natives. For example, the students had good access to available technologies, but had challenges in their use, for example, not knowing how to sign on and post to the discussion boards. Furthermore, though they tended to use the ICTs for social purposes, these students were somewhat reluctant to use them to interact with each other for academic purposes. The development among the students also tended to reflect what is noted in the literature. Students were enthusiastic about the online resources, but were specific about what would attract them. They wanted colour, graphics and ease of access. When these characteristics were incorporated into the resources, more of the students made use of the provisions. Of note is the fact that the students were initially reluctant to engage in the online discussions because they did not want to expose their lack of knowledge. In the Caribbean setting where students attending the more prestigious schools such as the one involved here are considered to be the top students, this reaction is not unusual. These students were not anxious to feel vulnerable in a learning situation. It took some cajoling from their teacher for them to engage in discussion in this forum. However, once they started, they acknowledged that it was worthwhile to have such discussion. They found it useful to know how their peers were thinking, and to have the conversations online for easy access later on. It was also encouraging to note that one year after the project began, there was a changing culture at the school. The school had upgraded its technological infrastructure and there was greater tolerance for portable electronic devices as learning tools. More students were bringing their devices to school and were using them both in and out of the classroom for learning.

The evidence from this study also brought to light some issues related to technological change in an educational setting. It revealed that, as is often the case with educational change, the teachers found the innovation valuable and beneficial, but perhaps due to their own lack of knowledge and expertise, they tended to be a bit slow in adopting it. As Schlechty (2001) points out, teachers "cannot do what they do not know how to do" (p. 162), and the identified challenges of time and inadequate access to equipment may be the teachers' way of masking their lack of confidence and competence in the use of technology to promote learning. A follow up study in the school after the introduction of the equipment, staff development opportunities and school policies on the use of ICTs could investigate these issues.

At the end of this research, several lessons were learned from this project, including:

- Seeing the value of an innovation does not mean that individuals will readily embrace it.

- Small acts that do not conform to the intent of the change can inadvertently affect the success of the change (e.g. emailing resources to students rather than pointing them to the discussion boards as intended).

- Using ICTs as tools for teaching and learning can break down the boundaries to learning by encouraging interaction across vast distances (Students can be in touch with their teachers even when in distant lands).

- Using ICTs in this way encourages students to cooperate and share with each other as they engage in learning activities; something that is not generally part of the educational tradition of the region.

- $\quad$ Though students may be enthusiastic about using the technology for socialising, they may not readily embrace it as a tool for learning, especially where they have to expose themselves or their lack of knowledge to others.

- $\quad$ Portable devices can be put to educational use, and though students may use them primarily for socialising, if the resources appeal to them and meet their learning needs, they are more likely to use these valued technologies for learning independently, outside the walls of the classroom. 
The findings of this study and the lessons learned can be of value to other schools across St. Vincent and the Grenadines, as well as across the region, and can also provide information for international comparisons. As more schools become equipped with information and communication technologies and as portable and other electronic devices become prevalent among students, the learning environment of schools can expand, extending beyond the walls of the classroom, beyond the school compound, and even beyond national boundaries. This would contribute greatly to the development of students, including those in the Caribbean, as independent, collaborative learners.

\section{References}

Barbados Ministry of Education, Youth Affairs and Sports (2003). Brief on the GOB/IDB/CDB Education Sector Enhancement Programme. Retrieved from http://www.reform.gov.bb

Bennett, S. \& Maton, K. (2010). Beyond the 'digital natives' debate: Towards a more nuanced understanding of students' technology experiences. Journal of Computer Assisted Learning, 26, 32331.

Burgess, R., Brathwaite, N., Raffoul, J., Vera, T., Fano, A. C., \& Legall, G. (2011). Secondary School Modernization Project (SEMP): Project completion report. Report on IADB Project TT00023. Retrieved from http://idbdocs.iadb.org/wsdocs/getdocument.aspx?docnum=36422789

Calvani, A., Fini, A., Ranieri, M., \& Picci, P. (2012). Are young generations in secondary school digitally competent? A study on Italian teenagers. Computers \& Education, 58, 797-807. doi:10.1016/j.compedu.2011.10.004

Clark, W., Logan, R., Luckin, A., Mee, A., \& Oliver, M. (2009). Beyond Web 2.0: Mapping the technology landscape of young learning. Journal of Computer Assisted Learning, 25, 56-69.

Cohen, L., Manion, L., \& Morrison, K. (2000). Research methods in education(5th ed.). London, UK: Routledge Falmer.

Davis, M. R. (2010). Social networking goes to school. Digital Directions, 3 (June 2010). Retrieved from http://www.edweek.org/dd/articles/2010/06/16/03networking.h03.html

Eynon, R. (2009). Harnessing technology: The learner and their context. Mapping young people's uses of technology in their own contexts - A nationally representative survey, A report for BECTA. Retrieved from http://webarchive.nationalarchives.gov.uk/20110130111510/http:/research.becta.org.uk/uploaddir/downloads/page_documents/research/reports/ht_learner_context_survey.pdf

Frei, S., Gammill, A., \& Irons, S. (2007). Integrating technology into the curriculum. Huntington Beach, CA: Shell Educational Publishing Inc.

Fullan, M. (2007). The new meaning of educational change ( $4^{\text {th }}$ ed.). New York: Teachers College Press.

Gaffer, K., Singh, L., \& Thomas, T. (2011). Are we ready for Web 2.0? Evidence from a Caribbean University. Caribbean Teaching Scholar, 1(2), 129-146.

Gaible, E. (2009). Survey of ICT and education in the Caribbean: A summary report, based on 16 country surveys. Washington, DC: infoDev / World Bank. Retrieved from http://www.infodev.org/en/Publication.441.html

Gay, L. R., Mills, G. E., \& Airasian, P. (2009). Educational research: Competencies for analysis and application (9th ed.). Upper Saddle River, NJ: Pearson.

Gilbert, P. K., \& Dabbagh, N. (2005). How to structure online discussions for meaningful discourse: A case study. British Journal of Educational Technology, 36(1), 5-18.

Helmer, J. W., \& Bloch, N. (2010). Teaching Geography from the blogsphere. The Geography Teacher, 7(2), 73-76. 
Hung, H. T., \& Yuen, S. C. (2010). Educational use of social networking technology in higher education. Teaching in Higher Education, 15(6), 703-714.

Hunter, A. B., Laursen, S. L., \& Seymour, E. (2006). Becoming a scientist, the role of undergraduate research in students' cognitive, personal and professional development. Science Education, 91(1), 3674.

Leacock, C. J., Warrican, S. J., \& Veira, A. K. (2013). Knowledge and practices relating to netbook use: The Voices of Primary School Children in St. Vincent and the Grenadines. In R. McBride \& M. Searson (Eds.), Proceedings of Society for Information Technology \& Teacher Education International Conference 2013 (pp. 3260-3266). Chesapeake, VA: AACE.

Warrican, S. J., Leacock, C. J., Veira, A. K., \& Thomas, K. (2012). Interim report. An unpublished evaluation report to the SVG Ministry of Education.

Li, Y., \& Ranieri, M (2010). Are 'digital natives' really digitally competent? - A study on Chinese teenagers. British Journal of Educational Technology, 41(6), 1029-1042. doi:10.1111/j.14678535.2009.01053.x.

Maton, K., \& Bennett, S. (2010). The use if ICT's at the University of Sydney: A report on the experiences of students and teaching staff. Office of the DVC(E), University of Sydney, Sydney.

Matthews, K. E., Andrews, V., and Adams, P. (2011). Social learning spaces and student engagement. Higher Education Research \& Development, 30(2), 105-120.

McMullin, B. (2005). Putting the learning back into learning technology. In G. O’Neill, S. Moore \& B. McMullin, (Eds.), Emerging Issues in the Practice of University Learning and Teaching. Dublin: AISHE, 2005. Retrieved from http://www.aishe.org/readings/2005-1/mcmullin-D01-M10-2004.pdf

Ministry of Education, St. Vincent and the Grenadines. (2011). Draft ICT in Education policy. Ministry of Education St. Vincent.

Ministry of Education, Trinidad and Tobago. (2010). Strategic report (Final). Retrieved from http://www.moe.gov.tt/spotlightPDFs/MOE_Strategy_Report_Nov_2010.pdf

Ministry of Education, Trinidad and Tobago. (2012). eCal ICT in education innovative award 2012. Retrieved from http://www.moe.gov.tt/ecal_ict.html

National Telecommunication Regulatory Commission. (2011). Statistics. Retrieved from http://ntrc.vc/index.php/ statisticspg

O’Donnell, M. (2006). Blogging as pedagogic practice: artefact and ecology. Asia Pacific Media Educator, 17(3), 5-19.

Oludipe, B. D. (2009) Secondary school teachers' perceived benefits of ICT to science teaching and learning. Retrieved from http://www.scribd.com/doc/14572475/Secondary-School-Teachersperceived-benefits-of-ICT-to-Science-Teaching-And-Learning

Papp, R. (2010). Virtual worlds and social networking: reaching the millenials. Journal of Technology Research, 2, 1-15.

Pearson, M., \& Naylor, S. (2006). Changing contexts: teacher professional development and ICT pedagogy. Education Information Technology, 11, 283-291.

Prensky, M. (2001). Digital natives, digital immigrants part 1. On the Horizon, 9(5), 1-6.

Reeves, T. C. (1998). The impact of media and technology in schools: A research report prepared for the Bertelsmann Foundation. Athens: The University of Georgia. Retrieved from http://itech1.coe.uga.edu/ treeves/edit6900/BertelsmannReeves98.pdf 
Salaway, G, \& Caruso, J. (2007). The ECAR study of undergraduate students and technology. EDUCAUSE: Boulder, CO.

Schlechty, P. (2001). Shaking up the school house: How to support and sustain educational innovation. San Francisco, CA: Jossey Bass.

Schrum, L., \& Levin, B. B. (2009). Leading $21^{\text {st }}$ century schools: harnessing technology for engagement and achievement. Thousand Oaks, CA: Sage.

Selwyn, N. (2009). The digital native - Myth and reality. Aslib Proceedings, 61(4), $364-379$. Retrieved from www.emeraldinsight.com/0001-253X.htm

Trucano, M. (2005). Knowledge maps: ICT in education. Retrieved from http://www.infodev.org/en/Publication.8.html

Warrican, S. J. (2006). Action research: A viable option for change. Journal of Curriculum Studies, $38(1), 1-14$.

Watson, D. M. (2001). Pedagogy before technology: rethinking the relationship between ICT and teaching. Education and Information Technologies, 6(4), 251-266.

Wheeler, S. (2001). Information and communication technologies and the changing role of the teacher. Journal of Educational Media, 26(1), 7-17.

Zaidieh, A. (2012). The use of social networking in education: Challenges and opportunities. World of Computer Science and Information Technology Journal, 2(1), 18-21.

Corresponding author: Andrea Veira, andreaveira@gmail.com

Australasian Journal of Educational Technology (C) 2014.

Please cite as: Veira, A. K., Leacock, C. J., \& Warrican, S. J. (2014). Learning outside the walls of the classroom: Engaging the digital natives. Australasian Journal of Educational Technology, 30(2), 227-244. 